\title{
DESIGN EDITORIAL E COMUNICAÇÃO: CONFIGURANDO PERCURSOS ECOSSISTÊMICOS PARA A DIVULGAÇÃO CIENTÍFICA
}

Suellen de Freitas Máximo

Mestranda do Programa de Pós-graduação

em Ciências da Comunicação - UFAM

suefrei@gmail.com

Dra. Ítala Clay de Oliveira Freitas

Prof.a. Doutora do Programa de Pós-graduação

em Ciências da Comunicação - UFAM

iclayfreitas@hotmail.com

Resumo: O texto é produzido na interface entre as discussões ecossistêmicas e o diálogo do design na produção de um conhecimento feito por ações investigativas e métodos/técnicas num estudo documental e reflexivo pautados por Munari (1997) Armstrong (2015) e Cardoso (2012). Tem como propósito caracterizar e compreender a realidade comunicativa da divulgação da ciência em revista em suas fases de concepção e visualização das mensagens visuais, ou seja, tecer possíveis relações que envolve os processos e efeitos na construção, engendramento e interpretação dos signos, que tem em mente o pensar da percepção do designer, a leitura do pesquisador e a compreensão do leitor.

Palavras-chave: comunicação, revistas científicas, design editorial, divulgação científica, ecossistemas comunicacionais

\begin{abstract}
The text is produced at the interface between ecosystem discussions and design dialog in the production of an acknowledgment done by probing actions and methods/techniques. It aims to characterize and understand the communicative reality of the dissemination of science reviewed in its phases of design and display of visual messages, weaving possible relationships involving the processes and effects in construction, engendering and interpretation of signs, which takes mind thinking of perception of the designer, the reading of the researcher and the reader's understanding .
\end{abstract}

Keywords: communication, scientific journals, editorial design, Science communication, communication ecosystems 


\section{INTRODUÇÃO}

O artigo apresenta uma abordagem ecossistêmica do design editorial na divulgação científica em revistas, apresenta um levantamento bibliográfico sobre revista científica, propõe um diálogo a respeito da concepção e visualização da comunicação científica empregadas pelo design editorial e busca tecer possíveis reflexões numa visão abrangente da área editorial.

Realiza o levantamento numa perspectiva histórica de revistas de divulgação científica, busca nas literaturas Población et al. (2011) textos que sejam úteis para o enredo do assunto em questão, assim, uso de um método de análise bibliográfica e documental.

Partindo do princípio de se ter um aparato geral no que tange a comunicação científica, a pesquisa apoia-se numa visão ecossistêmica, que deve ser considerada "um todo" onde independente do referencial adotado (objeto de estudo), possui diversas comunidades que irão lhe integrar, seja de forma hierárquica ou não, com Maturana (2001), Capra (2008) e Luhmman (1999) adotados como um esforço para sistematizar uma teoria de cooperação entre os diversos níveis.

Já no diálogo do design, na tentativa de esboçar conceitos chaves para a concepção e compreensão da comunicação que envolve a leitura das mensagens visuais, estudo documental e reflexivo pautados por Munari (1997) Armstrong (2015) e Cardoso (2012).

Diante deste contexto, é uma oportunidade e um desafio que norteiam um diálogo mais abrangente de fatores intermitentemente alocados na multiplicidade do saber, no qual requer um pensar ecossistêmico para auxiliar na tradução da complexidade que envolver a comunicação científica.

Desse modo, a pesquisa cumpre a função de viabilizar discussões, estudos e investigações no que tange aos sistemas que interferem de forma tanto positiva, quanto negativa na compreensão das configurações visuais da informação pelo leitor, desse modo contribuindo com a divulgação científica, acesso ao conhecimento e alfabetização visual.

Conhecimento este, que começa a entrar em outra esfera de comunicação, ultrapassando a barreira antes restrita a uma classe específica de pesquisadores no qual decodifica esse tipo de linguagem, para uma classe que começa a possuir habilidades, ainda que iniciais, para interpretar as informações contidas nestes meios de comunicação.

\section{DESENVOLVIMENTO}

\subsection{Da Epistolografia a revistas}

No limiar da evolução do processo de comunicação na ciência, no século XVII, as epistolografias eram as trocas de cartas entre os cientistas, configurando-se tal ato a primeira manifestação em se disseminar a ciência.

Carvalho (2012) diz que primeiras revistas assim dizendo, surgiram de um sistema privado organizado por grupos de cientistas (denominados colégios invisíveis) que a priori realizam encontros para realização de experimentos e discussões a respeito de dado fenômeno, no qual eram registrados para em seguida serem transformados em documentos que visavam a distribuição, e assim surge a necessidade de meios de comunicação, dessa forma legitimando-se a revista científica como tal meio e procedente para divulgação das mudanças e resultados científicos. 
Ao longo desse percurso, houve diversos avanços tecnológicos e sociais que deram subsídios a origem de novos suportes para tal comunicação, nas esferas de produtos editoriais, a configuração formal e estética da linguagem seja textual ou visual das revistas, é tida como uma publicação periódica de formato, segmentos, temáticas variadas e informação mais analítica e aprofundada, onde é possível ter melhor qualidade de papel, impressão, além de maior liberdade de técnicas e elementos de produção editorial no que tange a diagramação, uso de cores e tipografias.

$\mathrm{Na}$ sociedade, as revistas cumprem importante papel no que tange a informação, pois possui grande gama de segmentação, a esse ponto tangenciando a ciência pela sua diversidade de atuação em área ou eixos temáticos, e nos aspectos metodológicos, sendo primordial diferentes meios impressos para a comunicação, seja entre pares ou sociedade em geral, assim por dizer a Revista sendo um importante protagonista da produção científica.

No Brasil, há a divulgação científica em revistas, que estão diretamente ligadas a segunda revolução industrial (na segunda metade do século XIX), e mais adiante nos anos 80, destaca-se a revista Ciência Hoje

O objetivo de seus editores estava explícito no primeiro editorial: estabelecer um canal de comunicação entre a comunidade científica e o grande público; e promover o debate político em torno de questões como cidadania, educação e participação universitária, possibilitando, assim, a democratização da ciência. Para isso, era preciso superar um obstáculo que seria decisivo para impulsionar e sustentar o projeto original: substituir a linguagem hermética dos artigos científicos, carregada de jargões e fórmulas, por textos de maior simplicidade e clareza, sem perda do rigor científico. (IVANISSEVICH apud SANTOS, 2007, p.47)

Pois a partir de sua significativa atuação, foi possível a criação da revista Ciência Hoje das Crianças em 1986, assim como representa o marco no aparecimento de diversas revistas ligadas a divulgação científica, seja no âmbito de iniciativas privadas ou institucional, destacando-se de antemão esta última modalidade como objeto do artigo em questão.

Dessa forma, no âmbito institucional, é visualizado o impulsionamento das Revistas Científicas brasileiras, com enfoque em ensino, pesquisa, tecnologia e inovação, estas então direcionadas para a divulgação da ciência e amparadas por e pelo crescimento de fundações de amparo à pesquisa no Brasil, em que 1962, temos a primeira Fundação de Amparo à Pesquisa, a do estado de São Paulo (Fapesp). A partir desta, outros estados brasileiros passaram a estruturar suas próprias fundações, baseados no modelo da Fapesp.

O surgimento das Fundações de Amparo à Pesquisa (FAPs) revela-se um indicador seguro de novo modelo de se propor o desenvolvimento de CT\&I no Brasil, dessa forma, praticamente todo o território brasileiro possui uma Fap, com exceção de Roraima. E dentre este quantitativo, 7 (sete) instituições possuem o produto editorial e gráfico revista impressa como um dos meios para promover a divulgação da ciência como mostra a figura 1. 


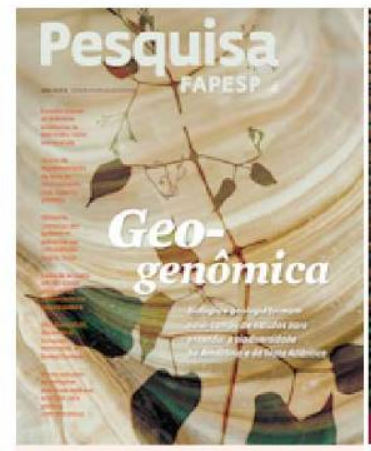

Pesquisa Fapesp
Fundaçă de Amparo à Pesquiso do

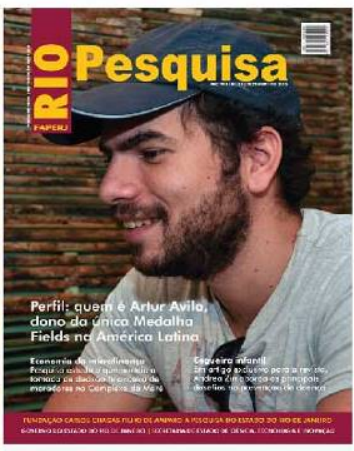

Rio Pesquisa

Fundaçăo Carlos Chagas Filho de Amparo à

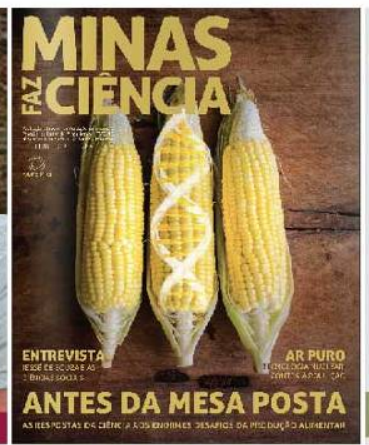
Minas faz Ciência Fundação de Amparo à Pes

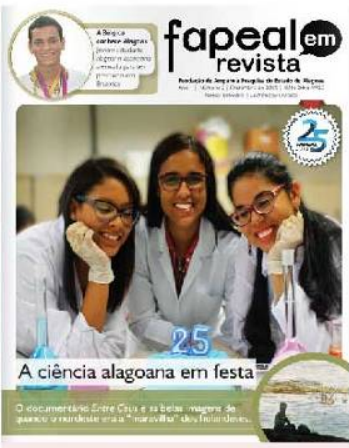

Fapeal em Revista Fundação de Ampar
de Alagoas - FAPEAL

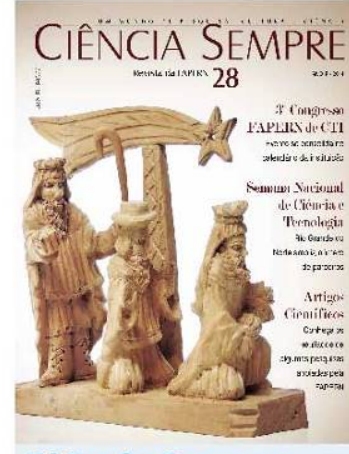

Ciência Sempre Fundação de Apoio à Pesquisa do Esta
do Rio Grande do Norte - FAPERN

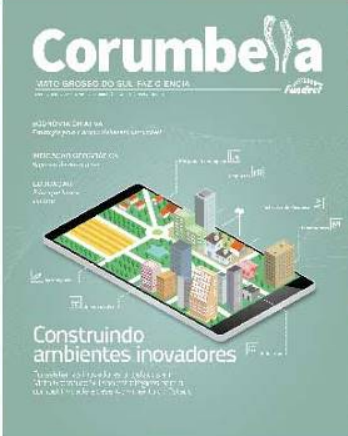

MS faz Ciência

Fundação de Apoio ao Desenvolvimento do Ensino, Ciência e Tecnologia do Estado de
Mato Grosso do Sul - FUNDECT

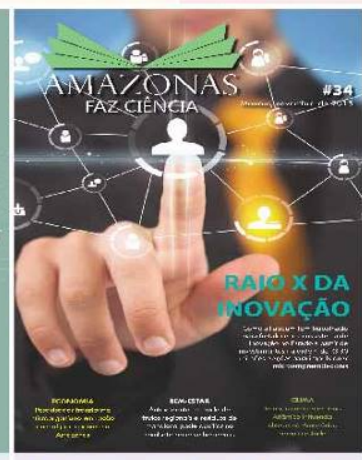

Amazonas faz Ciência Fundação de Amparo à Pesquisa do Estado do Amazonas - FAPEAM

Figura 1 - Relação de revistas de divulgação científica de Fundações de Amparo à Pesquisa no Brasil. Fonte: Elaborada pelo autor, com base na pesquisa realizada, 2016.

Diante desse levantamento, é importante o entendimento de modo sistêmico do processo da comunicação visual e seus fenômenos da divulgação científica de revistas impressas, de como compreender a complexidade existente neste meio, pois por si só o

o conhecimento científico também foi durante muito tempo e com frequência ainda continua sendo concebido como tendo por missão de dissipar a aparente complexidade dos fenômenos a fim de revelar a ordem simples a que eles obedecem. (MORIN, 2007, p.5)

Dessa forma, por si só a ciência é complexa, onde se torna primordial pensarmos na configuração do percurso do design editorial e da comunicação de modo generalizado, ou seja, no contexto ecossistêmico, em que por meio da junção de vários sistemas, estabelece-se uma unidade integrada, esta na qual deve ter interrelações nos diversos campos (social, cultural, tecnológica, científica entre outras) para ressaltar a compreensão da mensagem visual.

\subsection{O diálogo do design na concepção e visualização da comunicação científica}

Em um sentido global, design "...é concepção e planejamento de todos os produtos feitos pelo homem...". (FIELL e FIELL , 2000).

Por sua abrangência, estreitando-se o design para a área desta pesquisa, temos o design gráfico que surgiu em meados do século XX. 
Design gráfico é a atividade profissional e consequentemente a área de conhecimento cujo objeto é a elaboração de projetos para reprodução por meio gráfico de peças expressamente comunicativas. Essas peças - cartazes, páginas de revistas, capas de livros e de produtos fonográficos, folhetos etc. - têm como suporte geralmente o papel e como processo de produção a impressão. (VILLAS BOAS, 2007, p.30).

Mas além disso, o design gráfico "é visto como atividade que possui a ação de conceber, programar, projetar e realizar comunicações visuais, destinadas a transmitir mensagens específicas a grupos determinados". Aqui, deve-se considerar as sensações e experiências decorridas do público ao qual a informação é transmitida e levar em conta elementos adequados de tal contexto comunicativo.

Tais elementos, como formas, cores, grids entre outros são essências para a comunicação das formas de visualização de informações científicas em revistas, mas hoje, não só isso é fundamental para desenvolver produtos editoriais, é preciso investigar sobre a comunicação, os sistemas no qual a envolve, assim como a semiose, um processo de atividade característico da capacidade inata humana de produção e entendimento de signos das mais diversas naturezas necessárias entre eles.

Tendo em vista Munari (2007), quando se fala nessas novas formas de visualizações, investigações, tem-se novos problemas e novos instrumentos

portanto, uma formação baseada só no passado não tem utilidade alguma para o operador visual que deva operar em futuro próximo. 0 passado pode desempenhar apenas função de informação cultural, e deve estar ligado ao seu tempo, caso contrário não se entenderá mais nada. (MUNARI, 2007, p.06).

E pelo continuo processo de mudanças de informações em nosso dia a dia, a comunicação moderna, rápida, nos levou aos últimos limites da linguagem, sentiu-se a necessidade de recuperar as formas visuais da comunicação. E todo esse processo de comunicação através de imagens pertence ao amplo campo do design, pois o objetivo do design na comunicação visual é comunicar, de maneira clara e eficiente uma mensagem, agregando valores aos elementos visuais por meio de signos visuais, códigos cromáticos, enfim, uma série de recursos que unem à arte, a ciência, a psicologia, a semiótica, a tecnologia entre outros.

Desse modo, tendo em vista o pensamento "é precisamente a técnica que se pode ensinar, a técnica mais nova, não a arte" Munari (2007, p. 06), é perceptível um amplo espectro de significados no qual: um em que o mesmo adequa bastante a comunicação à técnica.

Já obstante desse pensamento, Cardoso (2011) também aponta o limiar do design na sua concepção original, nascido com o objetivo de colocar ordem na bagunça industrial.

Mas o mesmo autor pondera o real sentido do Design em um mundo hoje no qual trabalha-se o imaterial, haja visto com a expansão da tecnologia a explosão do meio digital.

Ou seja, essas novas formas de visualizações que afeta de modo geral diversos campos sociais, mas ponderamos aqui na comunicação científica, transforma de modo 
profundo a paisagem econômica, política, social e cultural. Em contraponto com Munari (2007), não se pode pensar apenas em técnicas, mas em diversos fatores inerentes a comunicação, tendo em vista a não dissipação de fatores, mas sim na complexidade em envolver partes de um todo.

Assim como em diversos campos no qual o Design opera, hoje temos a necessidade de comunicar por meio da ciência, em deixa-la mais próxima da sociedade como um todo, o design não pode ser visto apena como um operador de técnicas para solucionar problemas, mas como um ser que está no envoltório também dessa solução "se o design tem a ver com a vida, por que não teria ele toda a complexidade, variedade, contradição e sublimidade da vida?" (MCCOY \& MCCOY Apud ARMSTRONG, 2015, p. 101).

Desse modo, enfatiza a necessidade do design para um mundo complexo, onde

a pergunta é: como se opera esse processo de transpor qualidades perceptíveis visualmente para juízos conceituais de valor? Formulada de maneira mais simples, porém mais passível de gerar interpretações confusas: de que modo as formas expressam significados?. (CARDOSO, 2011, p.30).

Por esses aspectos é importante reflexões sobre comunicação e design editorial para as revistas de divulgação científica, ou seja, de tirar a cegueira existente e ser capaz de compreender a realidade comunicativa inserida na multiplicidade que requer a linguagem visual.

\subsection{0 percurso ecossistêmico do design editorial e da comunicação na divulgação científica}

A relação de proximidade entre diversos sistemas e meio podem compor uma visão ecossistêmica, tendo como base Capra (2006), o mesmo cita como conveniente resumir algumas características básicas do pensamento sistêmico. Esse estudo tem como sentença estabelecer primeiramente que os sistemas vivos são totalidades integradas cuja as propriedades não podem ser reduzidas, pois surgem das relações de organização, ou seja, mudança de partes para o todo, por conseguinte, com a capacidade de deslocar a própria atenção de um lado para outro em níveis sistêmicos.

Pode-se definir que possui uma ampla multidisciplinaridade, pois conforme cita MATURANA (2001) que também tem toda sua abordagem em ciências de cunho biológico, diz que diferentes sistemas compõem o ecossistema comunicacional:

então nós, as comunidades humanas, somos redes que se intersectam nas pessoas - redes de sistemas, alguns sociais e outros não sociais. E digo que é fundamental fazer essa distinção porque parte de nossos problemas em entender o que acontece com as diferentes comunidades humanas está em não entender os diferentes tipos de sistemas que configuramos, pois fazemos parte de sistemas sociais, de sistemas de trabalho, de sistemas hierárquicos. (MATURANA, 2001, p. 110).

Seu principal conceito é o da autopoiese, ou seja, um sistema que se auto regula. Esse conceito também ficará conhecido como a biologia do conhecer, pois caracteriza o conhecimento como a perturbação do sistema cognitivo, pois é possível 
fazer as mudanças nas estruturas, mas não nas organizações estruturais, ou seja, em suas identidades, mas haja visto que essa organização, entretanto, não é estática, porque sempre existe uma organização cognitiva, pois não é o exterior quem determina a experiência, o sistema sempre funciona a partir de correlações interiores.

Assim, enquanto Maturana (2001) restringem o conceito da autopoiesis a sistemas vivos, Luhmann (1999) o amplia para todos os sistemas em que se pode observar um modo de operação específico e exclusivo, que são, na sua opinião, os sistemas sociais e os sistemas psíquicos.

Destaca-se então no sistema social, no qual possui subsistemas de interação e organização que constituem a estrutura social que norteia as relações, a comunicação, a evolução linguística de cada ser vivo, visto que a comunicação é usada como modo particular de reprodução autopoiética dos sistemas sociais.

É importante destacar que há diferenciação entre os sistemas dentro do sistema, conforme cita Maturana (2001), "os diferentes tipos de sistemas que coexistem em uma mesma dimensão espaço-temporal" (p. 34).

Dessa forma, é possível caracterizar um sistema pesquisadores dentro do sistema social, no qual é o sistema que dar todo o aparato "conteúdo científico" para que haja, assim dizendo, uma devolutiva a sociedade, pois

os seres vivos, como sistemas determinados estruturalmente, são sistemas que, em sua dinâmica estrutural, se constituem e se delimitam como redes fechadas de produção de seus componentes, a partir de seus próprios componentes e de substâncias que tomam do meio: os seres vivos são verdadeiros redemoinhos de produção de componentes, em virtude do que as substâncias que tomam do meio, ou vertem no meio, seguem participando transitoriamente do ininterrupto intercâmbio de componentes que determina seu contínuo revolver produtivo. É esta condição de contínua produção de si mesmos, por meio da contínua produção e intercâmbio de seus componentes, o que caracteriza os seres vivos e é isto o que se perde no fenômeno da morte. (Maturana, 1985, p. 73).

Assim como para Luhmman (1999), os sistemas sociais são autorreferenciais porque são "capazes de operar com base em suas próprias operações constituintes" (p. 78). São autopoiéticos porque se autoreproduzem ou produzem a si mesmos enquanto unidade sistêmica.

Com isso, o sistema social se distingue de tudo o mais, inclusive dos seres humanos, assim como aponta que na medida em que o sistema social e o sistema psíquico operam de forma autopoiética e de forma separada, a sociedade é tida como entorno para o indivíduo: "os seres humanos são o entorno psíquico dos sistemas sociais" (Maturana, 1985, p. 81).

E é evidentemente diante deste contexto que há a grande lacuna no que tange o conhecimento científico, onde não basta apenas divulgar um fazer científico, ou seja, usar os sistemas pesquisadores (ciência) para desenvolver tal atividade, é importante o contexto psíquico e social de todo o sistema.

Assim como também, deve-se pensar no contexto político, havendo de antemão um sistema no qual deve ser considerado, mas ainda assim, isso não significa dizer que a consciência não tenha nenhum papel para os sistemas sociais: "sistemas 
sociais e consciências estão em estado de interpenetração, ou seja, cada um desses sistemas é condição de possibilidade do outro" (Luhmman, 1999, p. 60).

Diante desse contexto, é possível exemplificar um ecossistema comunicacional na figura 2 destacando-se os sistemas citados nesse estudo documental e reflexivo que dar aparato contextual na proposta de abordagem ecossistêmica do design editorial e da comunicação na divulgação da ciência em revistas.

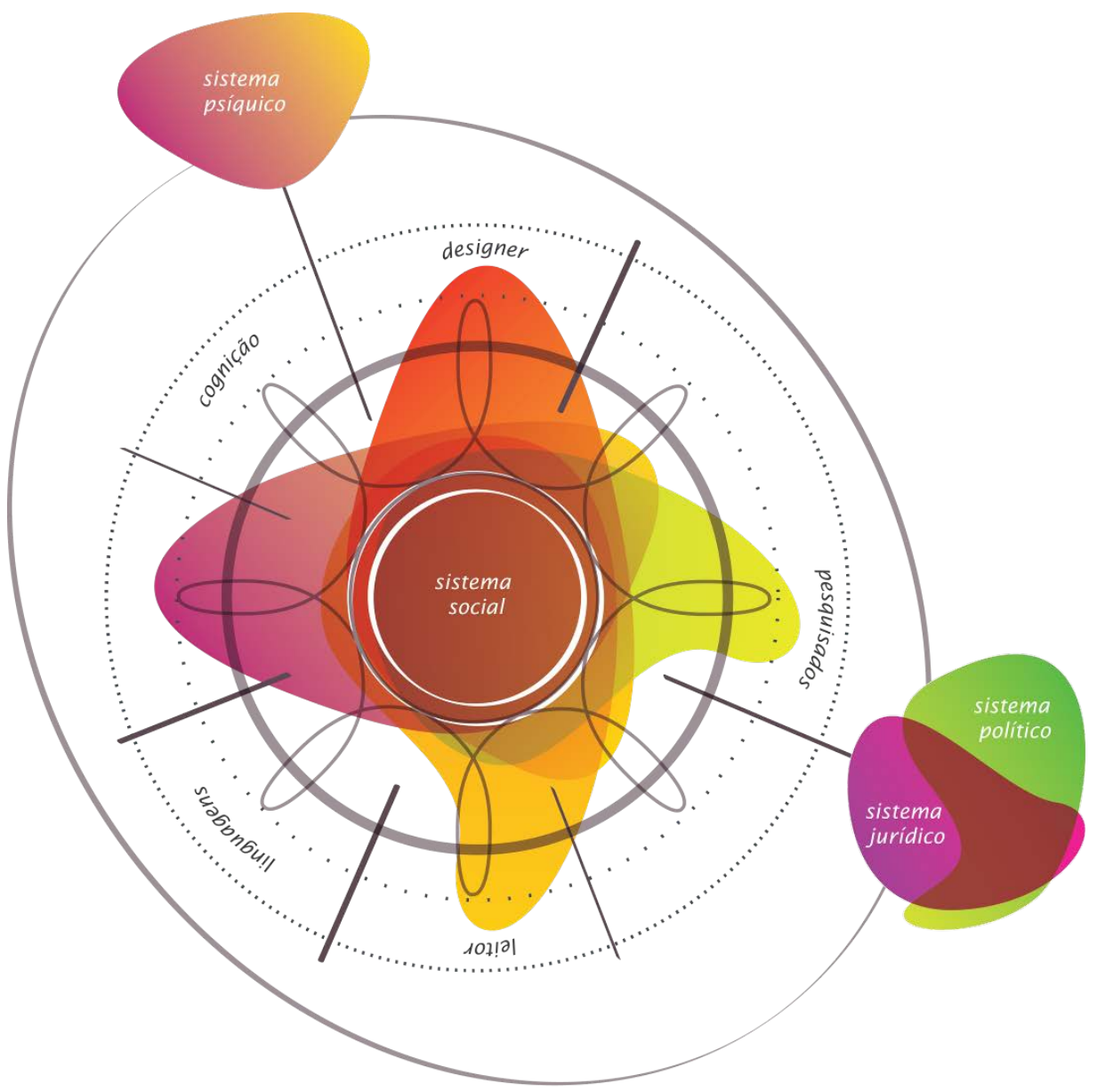

Figura 2 - Integração do percurso ecossistêmico de divulgação científica.

Fonte: Elaborada pelo autor, com base na pesquisa realizada, 2016.

\section{CONSIDERAÇÕES}

A proposta de configurar percursos ecossistêmicos do design editorial e da comunicação, compreende que a divulgação científica não pode ser analisada apenas na construção de diferentes discursos inseridos nas revistas, mas também das manifestações de linguagens contidas nas suas representações visuais, dessa forma, compreender o ecossistema que envolve o sistema de divulgação da ciência em revistas, por si só, gera informações que influenciem no processo de democratização do acesso ao conhecimento.

Por esses aspectos salienta-se aqui a importância da abordagem ecossistêmica que delimita comunicação, design e tecnologia, em revistas científicas, tirar a cegueira existente e ser capaz de compreender a realidade comunicativa inserida na 
multiplicidade que requer a comunicação, para assim compreender a semiose que envolve os processos e efeitos na construção, engendramento e interpretação dos signos e formas, que tem em mente o pensar da percepção do designer, a leitura do pesquisador e a compreensão do leitor.

Entretanto, mediante ao fato de que esta pesquisa está em andamento, pois é parte do estudo que vem sendo desenvolvido pela autora no Programa de PósGraduação em Ciências da Comunicação da Universidade Federal do Amazonas sob a orientação da Prof. Dra. Ítala Clay de Oliveira Freitas, e com o aporte financeiro da Fundação de Amparo à Pesquisa do Estado do Amazonas, é possível descrever breves caminhos no qual a pesquisa pretende percorrer.

Serão utilizados métodos da área Design editorial e dos fenômenos relacionados as linguagens, representações e estéticas no impresso. E nesta perspectiva, no que tange aos aspectos editoriais, pretende-se verificar e analisar os elementos visuais e a sua organização espacial, divididos nas seguintes categorias:

- Grids, utilizando método de Samara (2007) em que todo o trabalho do design envolve a solução de problemas em níveis visuais e organizativos, uso de grids (retangular, colunas, hierárquica e modular) em que por meio da diagramação é que se guia a leitura em um layout, identificando áreas principais para a distribuição espacial de títulos, textos, imagens, ilustrações, formas, cores na página entre outros.

Elementos da sintaxe visual que compreende (layout, cores, equilíbrio, contrates entre outros), utilizando método de Dondis (2007), White (2006) e Zappaterra (2014) no qual estabelece um compêndio de técnicas de edição de publicações no design gráfico e editorial.

E por fim nesta etapa editorial, uso de Gomes Filho (2003) para analisar as amostras da revista, levando-se em relação requisitos de: percepção, estrutura morfológica, estrutura cromática, estrutura tipográfica e estrutura tecnológica.

Já sob a perspectiva dos fenômenos relacionados a linguagens, direcionando os estudos de signos e interpretação ao uso em revistas amparado por Santaella (2007) fundadas na teórica de Pierce, ou seja, a estruturação do sistema a qual Pierce encaixou a semiótica, e ressalta a importância da compreensão dos símbolos, suas categorias e semiose. A essas categorias buscar-se-á também a análise dos signos nas revistas, juntando a percepção visual baseada na psicologia da forma por meio das Leis da Gestalt (Gomes Filho, 2003): unidade, unificação, segregação, fechamento, proximidade, semelhança, continuidade e pregnância da forma.

Portanto, é selecionada a revista Pesquisa Fapesp, como objeto de estudo para investigar e analisar as formas de visualizações das linguagens visuais da divulgação da Ciência, critérios pertinentes a: periodicidade, tempo de atuação e abrangência, foram primordiais para a seleção. Sua periodicidade é mensal, pode ser visualizada e salva no site da Fundação, assim como comprar em bancas de revista ou por assinatura. Sua tiragem é de 35.800 exemplares. (Revista Pesquisa Fapesp, 2009, on-line). Quarto ao recorte utilizado compreende o segundo semestre de 2015 conforme figura 3. 


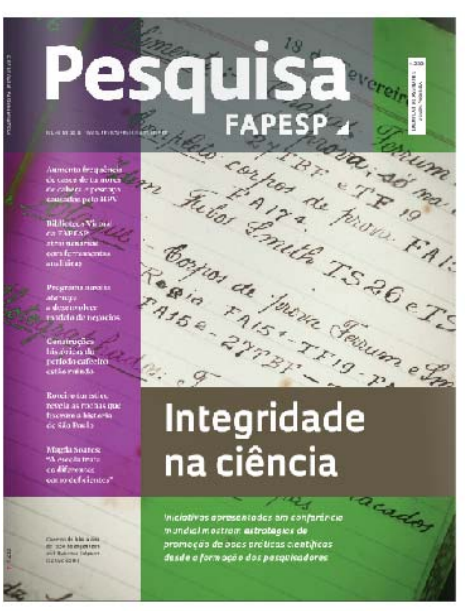

Ed. 233 Julho| 2015

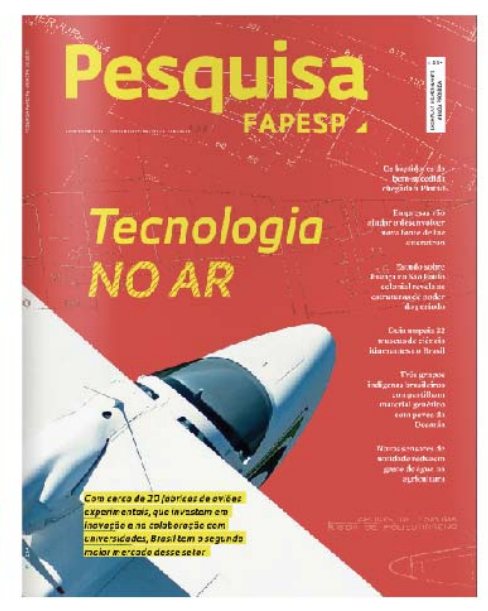

Ed. 234|Agosto|2015

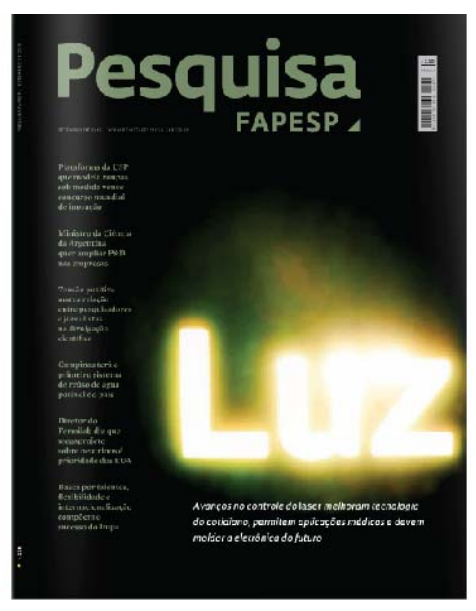

Ed. 235 Setembro|2015

\begin{tabular}{lll}
\hline Integridade na Ciência & Tecnologia no ar Luz \\
\hline
\end{tabular}

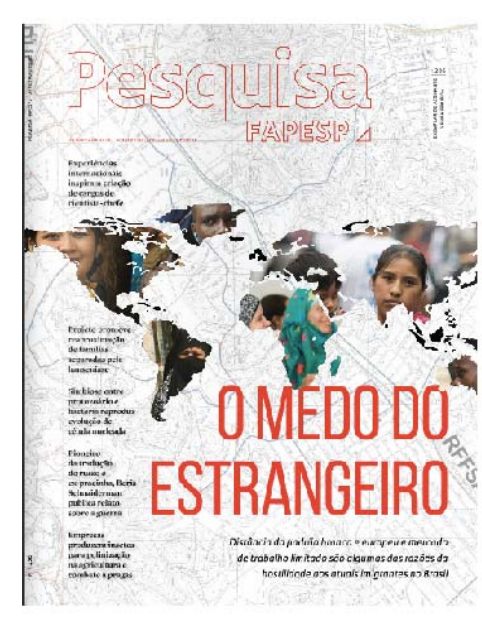

Ed. 236|Outubro|2015

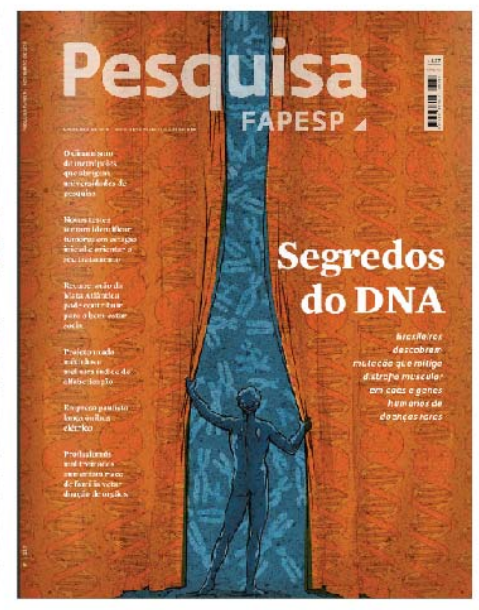

Ed. 237|Novembro|2015
Pesquisa

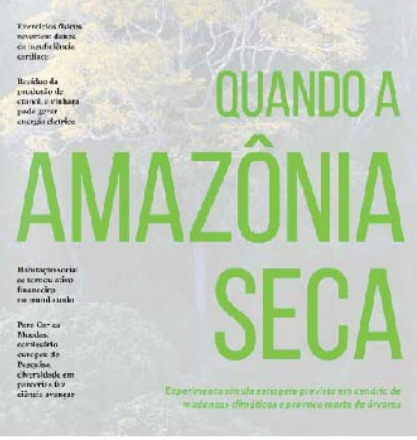

Ed. 238|Dezembro|2015

Quando a Amazônia seca

0 medo do estrangeiro

Segredo do DNA

\section{5).}

Fonte: Elaborada pelo autor, com base na pesquisa realizada, 2016.

Com estes exemplares, será feito um recorte do material a ser utilizado, selecionando-se algumas matérias para análises da percepção dos leitores durante a manipulação da revista, fazendo-se uso de materiais como máquinas fotográficas, filmadoras, formulários e softwares para compilação de dados.

Mas, a partir da reunião dos estudos e investigações na pesquisa, será possível detectar e estabelecer os principais critérios que interferem no percurso da compreensão da percepção visual da informação pelo leitor acerca das linguagens visuais em Ciência, logo, a coleta e análise dos dados poderão traduzir como as linguagens visuais empregadas pelo design editorial são perceptíveis em revistas científicas numa abordagem ecossistêmica no qual não somente envoltórios relacionados aos elementos utilizados traduzem essa significação mas também os sistemas envolvidos (social, psíquico, político e cognitivo). 


\section{REFERÊNCIAS}

ARMSTRONG, Helen. Teoria do Design Gráfico. Tradução: Marcondes, Claudio Alves. São Paulo: Cosac Naify, 2015.

BRUNO, Munari. Design e Comunicação Visual. São Paulo: Martins Fontes, 2011.

CARDOSO, Rafael. Design para um mundo complexo. São Paulo: Cosac Naify, 2012.

CAPRA, Fritjof. A teia da vida: uma nova compreensão científica dos sistemas vivos.

São Paulo: Cultrix, 2006.

DURAND, Gilbert. O imaginário: ensaio acerca das ciências e da filosofia da imagem.

Tradução: Renée Eve Levié. Rio de Janeiro: DIFEL. 4 edição, 2010.

LUHMANN, Niklas. Introdução a teoria dos sistemas. Rio de Janeiro: Editora Vozes. 2009.

MEADOWS, A. J. A comunicação científica. Brasília: Ed. Briquet de Lemos, 1999.MATHIS, Armin. A sociedade na teoria dos sistemas de Niklas Luhmann.

Disponível em: < http://www.infoamerica.org/documentos_pdf/luhmann_05.pdf>. Acesso em 23 de maio de 2015.

MATURANA, H \& VARELA, F. A Árvore do conhecimento. São Paulo: Palas Athena, 2005.

H. Cognição, ciência e vida cotidiana. Editora UFMG, Belo Horizonte,

2001.

MORIN, Edgar. Introdução ao pensamento complexo. Tradução: Eliane Lisboa. Porto Alegre: Sulina. 3 edição, 2007.

MUELLER, M. S. Popularização do conhecimento científico. Revista de Ciência e Informação, v. 3 n. 2, abr. 2002. Disponível em:

<http://www.dgz.org.br/abr02/art_03.htm>. Acesso em 14 de maio de 2015.

POBLACIÓN, Dinah; WITTER, Geraldina; RAMOS, Lúcia e FUNARO, Vânia (orgs.).

Revistas Científicas - Dos processos Tradicionais às perspectivas Alternativas de Comunicação. São Paulo: Ateliê Editorial, 2011.

SILVA, Juremir Machado. As tecnologias do imaginário. Porto Alegre: Sulina. 2 edição, 2006.

REVISTA PESQUISA FAPESP. Edição 241 - Março 2016. Disponível em: <

http://revistapesquisa.fapesp.br/revista/ver-edicao-editorias/?e_id=343>. Acesso em 29 de março de 2016.

REVISTA PESQUISA FAPESP. Quem somos. Disponível em:

http://www.revistapesquisa.fapesp.br/?art=3185\&bd=2\&pg=1 . Acesso em: 21 de abril de 2016.

STUMPF, Ida Regina Chitto. Revistas Universitárias, projetos inacabados. São Paulo: USP, 1994. (Tese de doutorado).

VILLAS-BOAS, A. O que é [e o que nunca foi] design gráfico. 6a revisada e ampliada. ed. Rio de Janeiro: 2AB, 2007. 